九州大学学術情報リポジトリ

Kyushu University Institutional Repository

\title{
Precise analysis and control of polymerization kinetics using a micro flow reactor
}

\section{Asano, Shusaku}

Department of Chemical Engineering, Kyoto University

Maki, Taisuke

Department of Chemical Engineering, Kyoto University

Nakayama, Ryutaro

Department of Chemical Engineering, Kyoto University

Utsunomiya, Ryuji

Department of Chemical Engineering, Kyoto University

他

http://hdl. hand le. net/2324/2235376

出版情報: Chemical Engineering and Processing: Process Intensification. 119, pp.73-80, 201709-01. Elsevier

バージョン :

権利関係 : 
Title of the article

\title{
Precise analysis and control of polymerization kinetics using a micro
}

\section{flow reactor}

\section{Authors}

Shusaku Asano ${ }^{\mathrm{a}}$, Taisuke Maki ${ }^{\mathrm{a}, *}$, Ryutaro Nakayama ${ }^{\mathrm{a}}$, Ryuji Utsunomiya ${ }^{\mathrm{a}}$, Yosuke Muranaka $^{\mathrm{a}}$, Toshiharu Kuboyama ${ }^{\mathrm{b}}$ and Kazuhiro Mae ${ }^{\mathrm{a}}$

a'Department of Chemical Engineering, Kyoto University, Kyoto, Japan

bSUMITOMO BAKELITE CO., LTD., Tokyo, Japan

*) Corresponding author

Taisuke Maki

Department of Chemical Engineering, Kyoto University, Kyoto-daigaku Katsura, Nishikyo-ku, Kyoto 615-8510 Japan

Tel.: +81-75-383-2688

E-mail: tmaki@cheme.kyoto-u.ac.jp

\begin{abstract}
Polymerization has a fast, complex reaction kinetics, which is difficult to control with conventional equipment. We employed a micro flow system to design ideal reaction conditions based on a kinetic model. Rate analysis was conducted at a wide range of reaction times, from 10 to $3600 \mathrm{~s}$. The concentration profile of an active intermediate was estimated and utilized for designing advanced reaction schemes, which required rapid
\end{abstract}


concentration and temperature changes. A block copolymer of hexyl norbornene and norbornene carboxylic acid alkyl ester was synthesized by developing a sequential polymerization system. The temperature jump operation, with $0.5 \mathrm{~s}$ initiation at $60{ }^{\circ} \mathrm{C}$ followed by $30 \mathrm{~s}$ propagation at $0^{\circ} \mathrm{C}$, generated a hexyl norbornene polymer with a sharp molecular weight distribution.

Keywords: polymerization kinetics, norbornene, micro flow reactor 


\section{Introduction}

A flow reactor with a small scale diameter, typically tens of microns to a millimeter, enables rapid mass and heat transfer via the short diffusion length, high surface to volume ratio and controlled secondary flows [1,2]. Therefore, a micro flow reactor is an attractive tool for producing fine chemicals and materials that require the strict control of process conditions for product quality [3,4]. For instance, monodispersed quantum dots were synthesized in a silicon carbide micro flow reactor with rapid heating [5]; a synthetic retinoid TAC-101 was synthesized via the $\mathrm{Br} / \mathrm{Li}$ exchange reaction with rapid mixing [6]; and zeolitic imidazolate flamework-8 particles with controlled sizes, shapes and gate adsorption characteristics were produced using a micromixer with 10 sub-streams [7]. Continuous flow synthesis also improves reproducibility [8] and productivity [9]. Therefore, small sized flow reactors, which do not necessarily have a microscale, have been intensively applied for on-demand production, especially of active pharmaceutical ingredients [10-12].

Micro flow reactors have been employed for precision polymerization for decades [13]. First, rapid mixing and heat removal have a significant advantage to make a sharp molecular weight distribution by providing strict control of the concentration and temperature. For example, improvement of molecular weight distributions in the radical polymerization of styrene [14], cationic polymerization of vinyl ether [15], and Grignard metathesis polymerization of 3-hexylthiophene [16] have been reported. Smaller polymer particles with a tighter size distribution were generated in an ultrasound-assisted, surfactant-free emulsion polymerization in a narrow channel reactor coil [17]. A tiny reaction volume with pressure resistance has advantages that allow us to safely conduct an unconventional reaction scheme that involves hazardous chemicals and high 
temperature and pressure. End group modification using trimethylsilyl azide at $120{ }^{\circ} \mathrm{C}$ and 20 bar, which would have explosion risks and the formation of extremely toxic $\mathrm{HN}_{3}$ gasses in a batch reactor, was successfully achieved in a commercial microchip [18]. The flow system can be equipped with in-line purification and process automation, which dramatically improve productivity and scalability. A modular flow system with a membrane separator achieved sequence defined polymer synthesis with a $66 \mathrm{~g} \mathrm{day}^{-1}$ throughput [19].

Almost all of the above polymerization studies with micro flow reactors have been empirically optimized by changing the temperature, residence time, concentrations and reactors, i.e., without kinetic modeling. One reason is probably the complexity of the polymerization mechanisms. However, optimization based on reaction kinetics would effectively improve the quality and productivity of the process. Kinetic modeling and micro flow reactors would have a strong synergy. Micro flow reactors can acquire reliable data for rate analysis by controlling the reaction time at a surprisingly high-resolution on the order of milliseconds [20]. Furthermore, the complicated behavior of secondary flows and concentration profile in a microreactor can be analyzed and optimized with the assistance of computational fluid dynamics simulation and 3D printing techniques [21]. An automated experiment that changes numerous variables is also possible with a compact system consisting of a micro flow reactor, pumps, and an analyzer [22]. Rapid heat and mass transfer enable us to realize the ideal conditions derived from the kinetic model, even if they require temperature changes within a second.

This study intended to invent a precision polymerization procedure based on polymerization kinetics. We chose the non-living coordination polymerization of norbornene derivatives as a model. Fig. 1 illustrates a proposed reaction mechanism for 
this system based on Barnes et al. [23]. Polymerization proceeds via insertion and coordination of a monomer to the nickel complex. There are two types of termination via proton transfer to an end group norbornene, where one is in the state of one monomer coordination (termination 1) and the other one is in the state of two monomer coordination (termination 2). This study attempted to acquire the kinetic parameter for each step and design a procedure to synthesize a block copolymer and a polymer with a monodispersed molecular weight distribution. These are challenging objectives in a non-living system in which an undesirable termination reaction exists. However, it would be a promising approach to intensify the versatility of polymer processing by expanding the scope of precision polymerization.

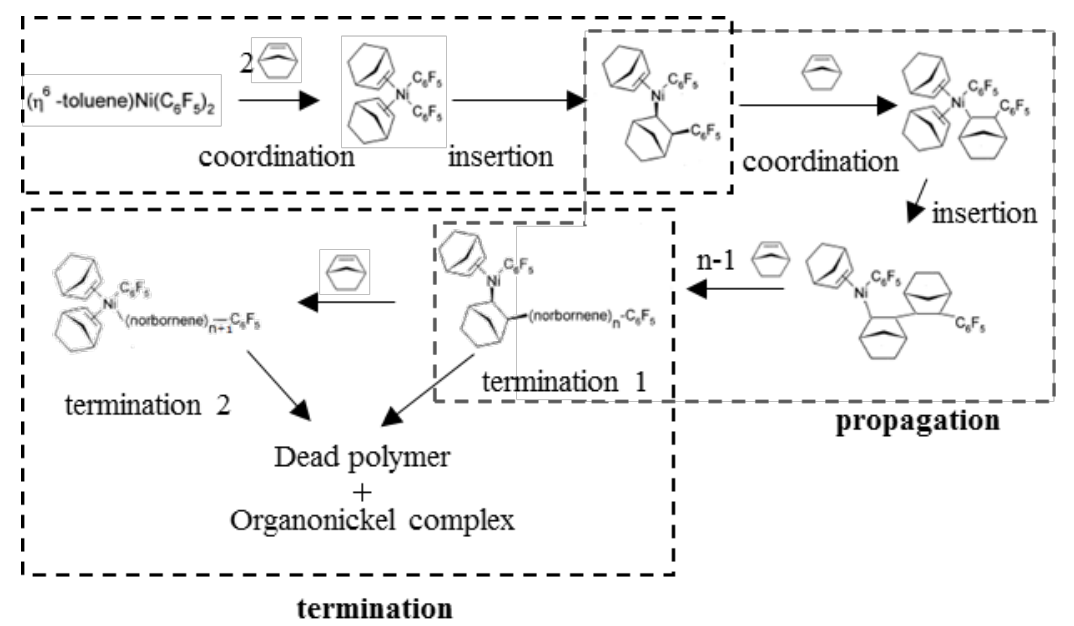

Fig. 1. Proposed reaction mechanism based on Barnes et al. [23]

\section{Methods}

\subsection{Materials}

Monomer materials of hexyl norbornene (monomer A) and norbornene carboxylic acid alkyl ester (monomer B) and an initiator of ( $\eta^{6}$-tolunene) $\mathrm{Ni}\left(\mathrm{C}_{6} \mathrm{~F}_{5}\right)_{2}$ were supplied from SUMITOMO BAKELITE (Tokyo, Japan). Toluene, tetrahydrofuran (THF), ethyl acetate, $30 \mathrm{wt} \%$ hydrogen peroxide, and acetic acid were purchased from Wako Pure 
Chemical Industries (Osaka, Japan). The monomer was diluted with a mixture of toluene and ethyl acetate at a weight ratio of 3:7. The prepared monomer solution was dried by bubbling with nitrogen gas for 30 minutes before usage. The initiator solution was prepared by diluting ( $\eta^{6}$-tolunene) $\mathrm{Ni}\left(\mathrm{C}_{6} \mathrm{~F}_{5}\right)_{2}$ with toluene. The aqueous peracetic acid solution for termination was prepared as THF $=27 \mathrm{wt} \%, \mathrm{H}_{2} \mathrm{O}=53 \mathrm{wt} \%, \mathrm{H}_{2} \mathrm{O}_{2}=8 \mathrm{wt} \%$, and $\mathrm{CH}_{3} \mathrm{COOH}=12 \mathrm{wt} \%$.

\subsection{Constant temperature polymerization for kinetic analysis}

Fig. 2(a) illustrates the reactor system. The reactor was constructed using SUS tubing and tees. Tubing with an outer diameter (o.d.) of 1/16” and an inner diameter (i.d.) of $1.0 \mathrm{~mm}$ was connected to union tees (Swagelok, USA) with an i.d. of $1.3 \mathrm{~mm}$. All tubing was coiled to enhance the heat and mass transfer and to reduce the residence time distribution [24,25]. The first tee mixes the monomer and initiator solution, and the other tee injects the peracetic acid solution to terminate the reaction. All were placed in a water bath to keep the temperature constant. The reaction time was controlled by changing the flow rate and length of tubing between tees. Two meters of tubing was used for reaction times from 10 to $20 \mathrm{~s}, 5 \mathrm{~m}$ of tubing was used for 30 to $60 \mathrm{~s}$, and $10 \mathrm{~m}$ of tubing was used for 150 to 3600 s. Four concentration sets were examined. The monomer A ([M]) and initiator ([I]) concentrations after the first tee for each set are listed as follows:

set 1 (monomer $5 \mathrm{wt} \%$ ): $[\mathrm{M}]=0.25 \mathrm{M},[\mathrm{I}]=0.0049 \mathrm{M}$

set 2 (monomer $10 \mathrm{wt} \%$ ): $[\mathrm{M}]=0.49 \mathrm{M},[\mathrm{I}]=0.0049 \mathrm{M}$

set 3 (monomer $15 \mathrm{wt} \%$ ): [M] $=0.74 \mathrm{M},[\mathrm{I}]=0.0049 \mathrm{M}$

set 4 (monomer $14 \mathrm{wt} \%$ ): $[\mathrm{M}]=0.68 \mathrm{M}$, [I] $=0.0048 \mathrm{M}$.

The ratios of the flow rates of the monomer solution, $5 \mathrm{~kg} \mathrm{~m}^{-3}$ initiator solution, and terminator solution were $0.86: 1: 1$ for set 4 and $1.3: 1: 1$ for the other sets. The flow 
rate was controlled using PHD Ultra syringe pumps (Harvard Apparatus, Massachusetts, USA).

To confirm that the kinetic parameters were not contaminated by heat and mass transfer issue, which originates from the enhanced viscosity with molecular weight build up, we measured the viscosity of a polymer solution. The sample polymer solution was obtained by polymerization in a batch reactor. Set 4 concentration was employed. A conical flask placed in a water bath at $25^{\circ} \mathrm{C}$ was used as a batch reactor. Air was purged with nitrogen gas before the injection of initiator solution. After $1 \mathrm{~h}$ reaction, kinematic viscosity of the solution was measured by an Ostwald viscometer with an inner diameter of $1.75 \mathrm{~mm}$ (As One, Osaka, Japan). Terminator solution was not added for measuring the viscosity before the dilution. The density of the solution was also obtained by weighing the $1 \mathrm{~mL}$ solution to convert kinematic viscosity to absolute viscosity.

\subsection{Block copolymer synthesis}

Fig. 2(b) illustrates the reactor system. Union tees with an i.d. of $0.33 \mathrm{~mm}$ were used. The first tee mixes the monomer A and initiator solutions. The second tee mixes the reacting stream and the monomer $\mathrm{B}$ solution. The third tee injects the terminator. Two water baths were used to change the temperature from $40{ }^{\circ} \mathrm{C}$ to $25^{\circ} \mathrm{C}$. The lengths of tubing were $2 \mathrm{~m}$ for both the first and second steps. The concentrations after the first tee were $[\mathrm{M}]=0.61 \mathrm{M}$ and $[\mathrm{I}]=0.0043 \mathrm{M}$. The concentration of monomer $\mathrm{B}$ was $0.825 \mathrm{M}$ after the second tee. The residence times were $30 \mathrm{~s}$ and $15 \mathrm{~s}$ for the first and second steps, respectively. The flow rates were $0.85,0.73,1.58$, and $3.16 \mathrm{~mL} \mathrm{~min}^{-1}$ for the monomer $\mathrm{A}$ solution, initiator solution $\left(5 \mathrm{~kg} \mathrm{~m}^{-3}\right)$, monomer B solution, and terminator solution, respectively. All other conditions were the same as described in section 2.2. For the 
control experiments, polymerization of monomer A alone with the first step and the block copolymer synthesis with twice the residence time $\left(60 \mathrm{~s}\right.$ for the $1^{\text {st }}$ step and $30 \mathrm{~s}$ for the $2^{\text {nd }}$ step) and with half the flow rate $\left(0.43,0.37,0.79\right.$ and $\left.1.08 \mathrm{~mL} \mathrm{~min}^{-1}\right)$ were conducted.

\subsection{Homopolymer synthesis with temperature jump}

Fig. 2(b) illustrates the reactor system. Of note, a $0.13 \mathrm{~m}$ length of tubing with an i.d. of $0.5 \mathrm{~mm}$ was used for the high temperature zone; a $2 \mathrm{~m}$ length of tubing with an i.d. of $1 \mathrm{~mm}$ was used for the low temperature zone. A water bath with a drilled screw hole was placed in a larger bath. Two tubes were connected at the drilled hole. The inner bath was kept at $60{ }^{\circ} \mathrm{C}$ by a heater. The outer bath was maintained at $0{ }^{\circ} \mathrm{C}$ with ice. The residence times were $0.5 \mathrm{~s}$ and $30 \mathrm{~s}$ for the low and high temperature zones, respectively. The flow rates were $1.44,1.70$, and $1.57 \mathrm{~mL} \mathrm{~min}^{-1}$ for the monomer A solution, initiator solution (30 $\mathrm{kg} \mathrm{m}^{-3}$ ), and terminator solution, respectively. The concentrations after the first tee were $[\mathrm{M}]=1.0 \mathrm{M}$ and $[\mathrm{I}]=0.033 \mathrm{M}$. All other conditions were the same as those described in section 2.2. For a control experiment, constant temperature operations for a 0.5-s reaction time at $60{ }^{\circ} \mathrm{C}$ and for a 30-s reaction time at $0{ }^{\circ} \mathrm{C}$ were conducted by removing one of the tubes.

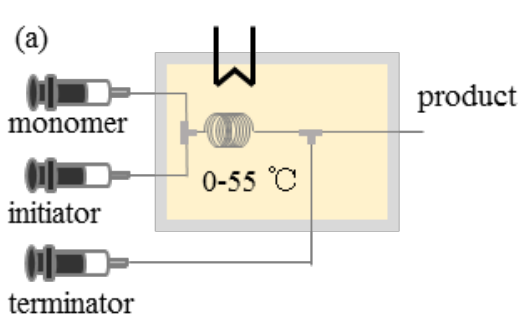

(b)

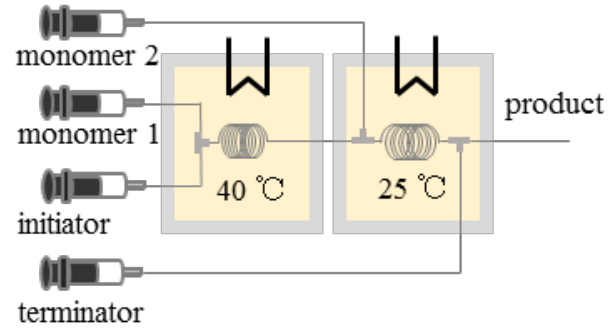




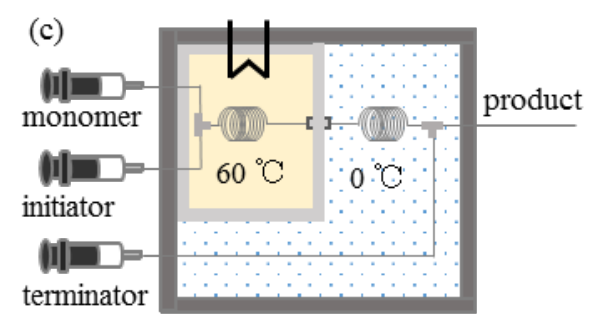

Fig. 2. Reactor setups: (a) constant temperature operation for kinetic analysis; (b) block copolymer synthesis; and (c) homopolymer synthesis with a temperature jump

\subsection{Analysis}

Conversion of the monomer was calculated from the monomer concentration in the solution after the reaction as determined by gas chromatography. A GC-2010 (Shimadzu, Kyoto, Japan) equipped with a flame ionization detector and a non-polar capillary column TC-1 (GL-Science, Tokyo, Japan) was used. Molecular weight distributions were obtained by high-performance liquid chromatography (HPLC). The separation column was a Shodex GPC LF-804 column (Showa Denko, Tokyo, Japan). A refractive index detector RID-6A (Shimadzu) and esa Corona charged aerosol detector (DIONEX, California, USA) combined with an SPD-20A UV detector (Shimadzu) were used as detection units. THF was used as the mobile phase with a $1 \mathrm{~mL} \mathrm{~min}^{-1}$ flow rate and was pumped with a LC10-ATvp HPLC pump (Shimadzu). Gradient polymer elution chromatography (GPEC) was conducted to analyze the composition and homogeneity of a copolymer. An Alliance 2695 HPLC system (Waters, Massachusetts, USA) equipped with a Luna C18(2) separation column (Phenomenex, California, USA) with a 2420 evaporative light scattering detector (Waters) was employed for GPEC. The flow rate of the mobile phase was fixed at $1 \mathrm{~mL} \mathrm{~min}^{-1}$. A mixture of acetonitrile and THF was used as the mobile phase. The linear gradient was adapted, and the percentage of THF was changed from $40 \%$ to $100 \%$ over 7.5 min after 0.5 min of operation. The composition 
was again changed from $100 \%$ to $40 \%$ over 0.5 min after 11 min of operation.

\subsection{Parameter fitting}

A kinetic model based on the mechanism in Fig. 1 was built as shown below.

$\begin{array}{llll}\text { Initiation } & \text { Coordination } 1 & \mathrm{I}+\mathrm{M} \rightleftarrows \mathrm{R}_{0} & r=k_{\mathrm{I} 1}[\mathrm{I}][\mathrm{M}]-k_{-\mathrm{I} 1}\left[\mathrm{R}_{0}\right] \\ & \text { Coordination } 2 & \mathrm{R}_{0}+\mathrm{M} \rightleftarrows \mathrm{R}_{1} & r=k_{\mathrm{I} 2}\left[\mathrm{R}_{0}\right][\mathrm{M}]-k_{-\mathrm{I} 2}\left[\mathrm{R}_{1}\right] \\ & \text { Insertion } & \mathrm{R}_{1} \rightarrow \mathrm{P}_{1} & r=k_{\mathrm{I} 3}\left[\mathrm{R}_{1}\right] \\ \text { Propagation } & \text { Coordination } & \mathrm{P}_{n} *+\mathrm{M} \rightleftarrows \mathrm{R}_{n+1} & r=k_{\mathrm{M}}\left[\mathrm{P}_{n} *\right][\mathrm{M}]-k_{-\mathrm{M}}[\mathrm{R} \\ & & & \left.{ }_{n+1}\right] \\ & \text { Insertion } & \mathrm{R}_{n} \rightarrow \mathrm{P}_{n} * & r=k_{\mathrm{P}}\left[\mathrm{R}_{n}\right] \\ \text { Termination } & \text { Termination 1 } & \mathrm{P}_{n} * \rightarrow \mathrm{P}_{n} & r=k_{\mathrm{T} 1}\left[\mathrm{P}_{n} *\right] \\ & \text { Termination 2 } & \mathrm{R}_{n} \rightarrow \mathrm{P}_{n-1} & r=k_{\mathrm{T} 2}\left[\mathrm{R}_{n}\right]\end{array}$

M: Monomer $\quad \mathrm{P}_{i}^{*}$ : Active intermediate with polymerization degree $i$

I: Initiator $\quad \mathrm{P}_{i}$ : Dead polymer with polymerization degree $i$

$\mathrm{R}_{i}$ : Monomer coordinated complex with polymerization degree $i$.

The number of parameters was reduced from ten to five by introducing the quasi-steady state assumption for the concentration of $\mathrm{R}_{\mathrm{i}}$. The simplified kinetic model is shown below:

Initiation

Propagation

$$
\begin{gathered}
\mathrm{I}+2 \mathrm{M} \rightarrow \mathrm{P}_{1}^{*} \quad r_{\mathrm{i}}=k_{\mathrm{I} 1}[\mathrm{I}][\mathrm{M}]^{2} /\left(k_{\mathrm{I} 2}+[\mathrm{M}]\right) \\
\mathrm{P}_{n}{ }^{*}+\mathrm{M} \rightarrow \mathrm{P}_{n+1}{ }^{*} \quad r_{\mathrm{p}}=k_{\mathrm{P}}\left[\mathrm{P}_{n} *\right][\mathrm{M}]
\end{gathered}
$$

$$
\begin{array}{lll}
\text { Termination } & \text { Termination } 1 & \mathrm{P}_{n} * \rightarrow \mathrm{P}_{n} r_{\mathrm{t}}=k_{\mathrm{t} 1}\left[\mathrm{P}^{*}\right] \\
& \text { Termination 2 } & \mathrm{P}_{n} *+\mathrm{M} \rightarrow \mathrm{P}_{n} r_{\mathrm{t}}=k_{\mathrm{t} 2}\left[\mathrm{P}^{*}\right][\mathrm{M}]
\end{array}
$$

Ordinary differential equations for parameter fitting were derived from the above model using the method of Carvalho [26]. The calculation cost was reduced by introducing supporting variables $X_{i}$ and $Y_{i}$. All experimentally obtainable variables, the monomer concentration, the number averaged molecular weight $M_{\mathrm{n}}$, and the weight averaged molecular weight $M_{\mathrm{w}}$, were included in the equations as follows:

$$
X_{i}=\sum_{n=1}^{\infty} n^{i}\left(\left[\mathrm{P}_{n}^{*}\right]+\left[P_{n}\right]\right)
$$




$$
\begin{gathered}
Y_{i}=\sum_{n=1}^{\infty} n^{i}\left[\mathrm{P}_{n}^{*}\right] \\
\frac{\mathrm{d}[\mathrm{I}]}{\mathrm{d} t}=-\frac{\mathrm{d} X_{0}}{\mathrm{~d} t}=-r_{\mathrm{i}} \\
\frac{\mathrm{d}[\mathrm{M}]}{\mathrm{d} t}=-r_{\mathrm{p}}-r_{\mathrm{t} 2}-r_{\mathrm{i}} \\
\frac{\mathrm{d}\left[\mathrm{P}^{*}\right]}{\mathrm{d} t}=\frac{\mathrm{d} Y_{0}}{\mathrm{~d} t}=r_{\mathrm{i}}-r_{\mathrm{t} 1}-r_{\mathrm{t} 2} \\
\mathrm{~d} t=r_{\mathrm{p}}+r_{\mathrm{i}}-k_{\mathrm{t} 1} Y_{1}-k_{\mathrm{t} 2}[\mathrm{M}] Y_{1} \\
\frac{\mathrm{d} X_{1}}{\mathrm{~d} t}=r_{\mathrm{p}}+r_{\mathrm{i}} \\
\frac{\mathrm{d} X_{2}}{\mathrm{~d} t}=2 k_{\mathrm{p}}[\mathrm{M}] Y_{1}+r_{i} \\
M_{\mathrm{n}}=\frac{X_{1}}{X_{0}} M \\
M_{\mathrm{w}}=\frac{X_{2}}{X_{1}} M
\end{gathered}
$$

where $M$ indicates the molecular weight of a monomer. Five parameters were simultaneously fitted for minimizing the sum of squared errors of the normalized monomer concentration, $M_{\mathrm{n}}$, and $M_{\mathrm{w}}$. Data analysis software IGOR Pro (HULINKS, Tokyo, Japan) was used for fitting. The value of $k_{\mathrm{i} 2}$ always took the negligibly smaller compared with the value of [M] when we fit the five parameters. So we emit $k_{\mathrm{i} 2}$ and recalculated other four parameters all at once.

\subsection{Polymerization simulation}

The Kinetic Monte Carlo (kMC) method, modified for polymerization simulation [27], was adopted to simulate molecular weight distributions from a reaction model and reaction conditions. The code was written in $\mathrm{C}++$ and run by Visual Studio 
2010. The basic algorithm of the kMC method is as follows:

1. Initialize reaction time $t$ as 0

2. Form a list of reaction rates, $r_{i}(i=1 \ldots n)$, for all possible reactions

3. Calculate $R_{i}$ for $i=1 \ldots n$ as $R_{i-1}=\sum_{j=1}^{i} r_{j}$, where $n$ is the total number of transitions

4. Get a random number $u(0<u \leq 1)$.

5. Find the transition event $i$ that satisfies $R_{i-1}<u R_{n} \leq R_{i}$

6. Carry out the event $i$ associated with $r_{i}$

7. Obtain a new random number $u$ '

8. Advance $t$ by $\Delta t=R_{n}^{-1} \ln \left(1 / u^{\prime}\right)$

9. Update all $r_{i}(i=1 \ldots n)$ affected by this move

10. Return to 3 until $t$ reaches the total polymerization time.

\section{Results and discussion}

\subsection{Constant temperature polymerization}

The results for constant temperature polymerization are shown in Fig. 3. Markers in Fig. 3 show the conversion of the monomer, $M_{\mathrm{n}}$, and $M_{\mathrm{w}}$ against the reaction time at each temperature and monomer concentration. First, we confirmed the successful termination of the polymerization by peracetic acid. The monomer concentration of the obtained solution did not change after it was maintained at room temperature for days. Peracetic acid solution would instantly deactivate the end group by protonation of the end group. Second, we also confirmed that the viscosity issue was negligible. Obtained absolute viscosity of the polymer solution was only $32.6 \mathrm{mPa} s$ after $1 \mathrm{~h}$ reaction with monomer $14 \mathrm{wt} \%$ at $25^{\circ} \mathrm{C}$. The polymer solution maintained the fluidity and neither gelation nor adhesion to the wall occurred. The increase in the temperature significantly accelerated the reaction; conversion reached $50 \%$ at $30 \mathrm{~s}$ at $55{ }^{\circ} \mathrm{C}$ and at $3600 \mathrm{~s}$ at $0{ }^{\circ} \mathrm{C}$ 
for the same concentration set (Fig. 3(a) and (f)). On the other hand, $M_{\mathrm{n}}$ and $M_{\mathrm{w}}$ decreased at the higher temperature; the $M_{\mathrm{n}}$ at $55^{\circ} \mathrm{C}$ was approximately one tenth of the $M_{\mathrm{n}}$ at $0{ }^{\circ} \mathrm{C}$ with the same concentration set. Increasing the monomer concentration increased both the conversion and molecular weight (Fig. 3(a) and (b), (f) and (g)). This supports the reaction model shown in Fig. 1 in which the monomer is involved in initiation and propagation, while it is not involved in termination. The temperature dependence of the polymerization steps can be qualitatively estimated from these results. The termination step should have a greater temperature sensitivity than the propagation step to satisfy the tendency of the molecular weight. The initiation step should have a larger sensitivity than the termination step to make conversion larger with a higher termination reaction rate. The best fit results obtained by the procedure described in section 2.6 are shown in Fig. 3 with lines. The fitted curves represent the experimental data well, indicating the validity of the reaction models. The frequency factor $k_{0}$ and activation energy $E$ were determined by the Arrhenius plots shown in Fig. 4 and are listed in Table 1. All $E$ values were in the reasonable range, and the order of each step agreed with the previously discussed temperature dependency, with initiation $>$ termination $>$ propagation.
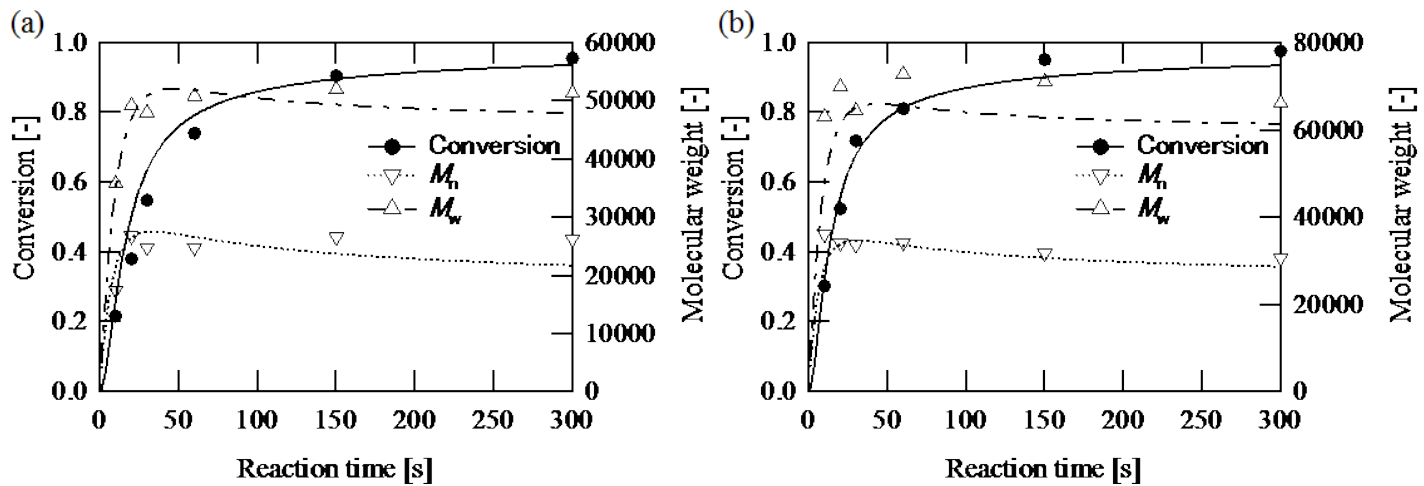

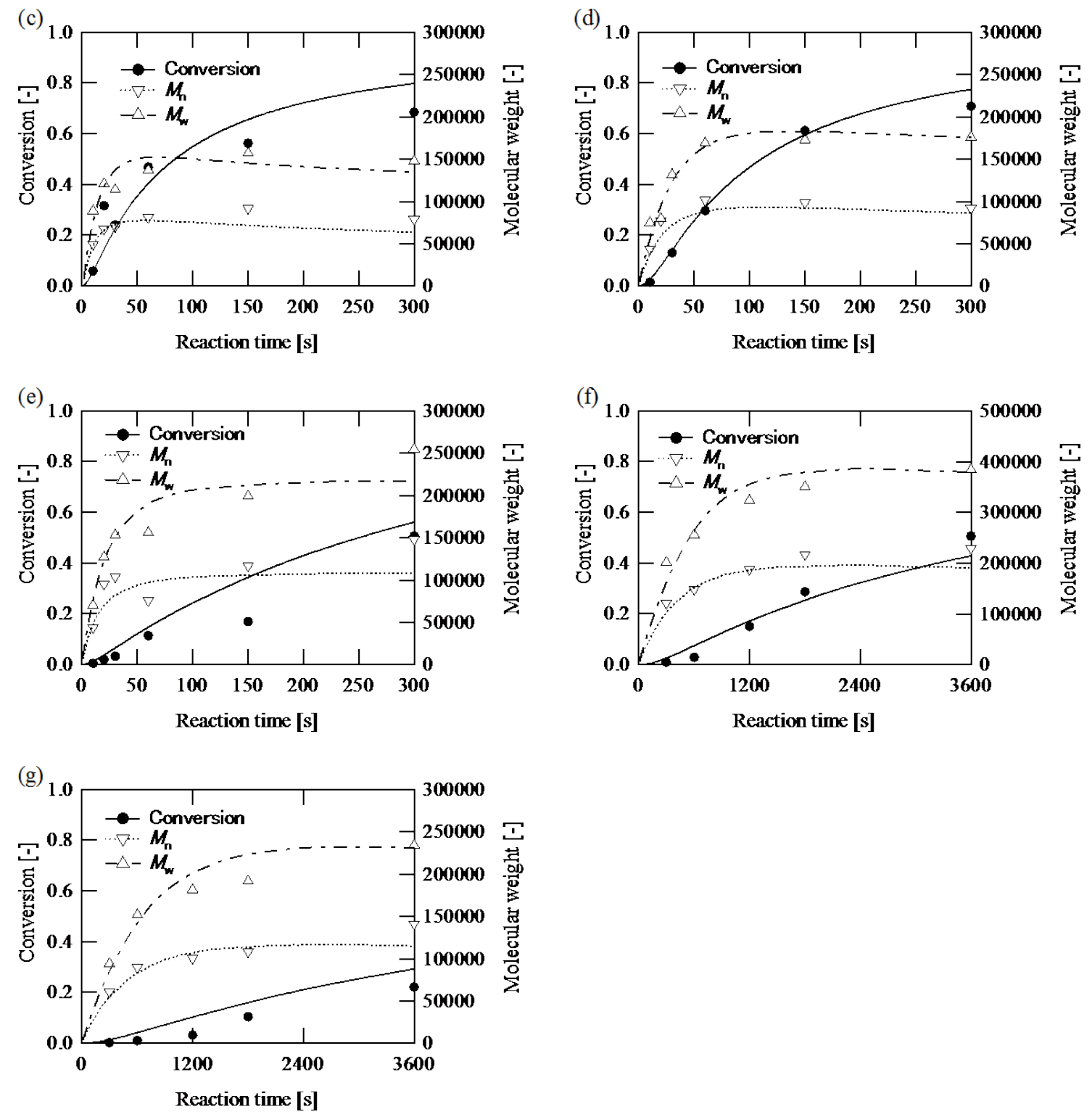

Fig. 3. Reaction results with model fitting: (a) $55^{\circ} \mathrm{C}, 10 \mathrm{wt} \%$; (b) $55^{\circ} \mathrm{C}, 15 \mathrm{wt} \%$; (c) $40^{\circ} \mathrm{C}$, $14 \mathrm{wt} \%$; (d) $33^{\circ} \mathrm{C}, 14 \mathrm{wt} \%$; (e) $25^{\circ} \mathrm{C}, 14 \mathrm{wt} \%$; (f) $0^{\circ} \mathrm{C}, 10 \mathrm{wt} \%$; and (g) $0{ }^{\circ} \mathrm{C}, 5 \mathrm{wt} \%$
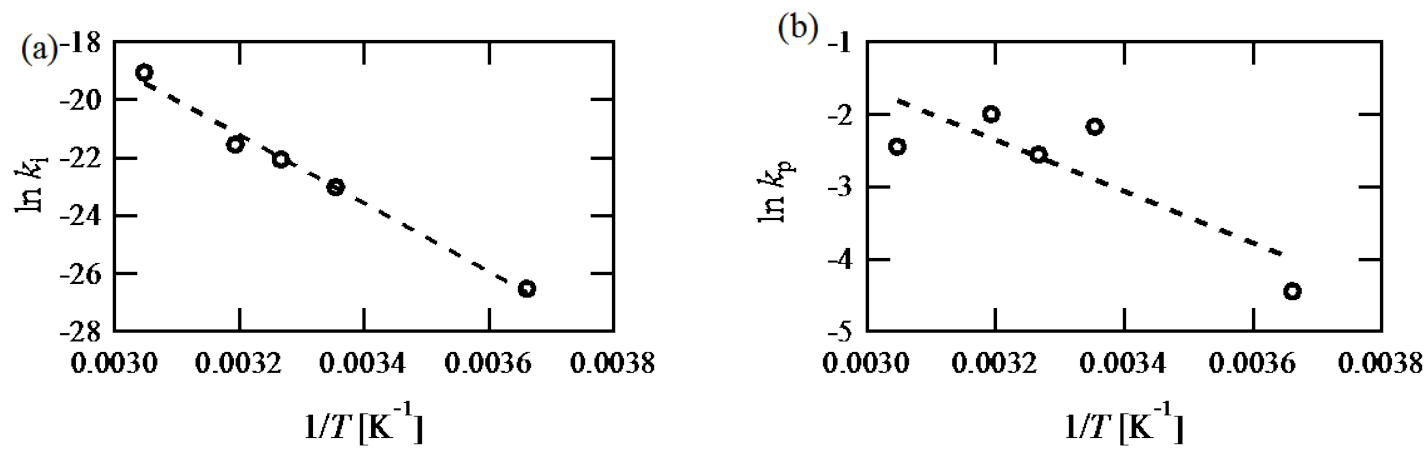

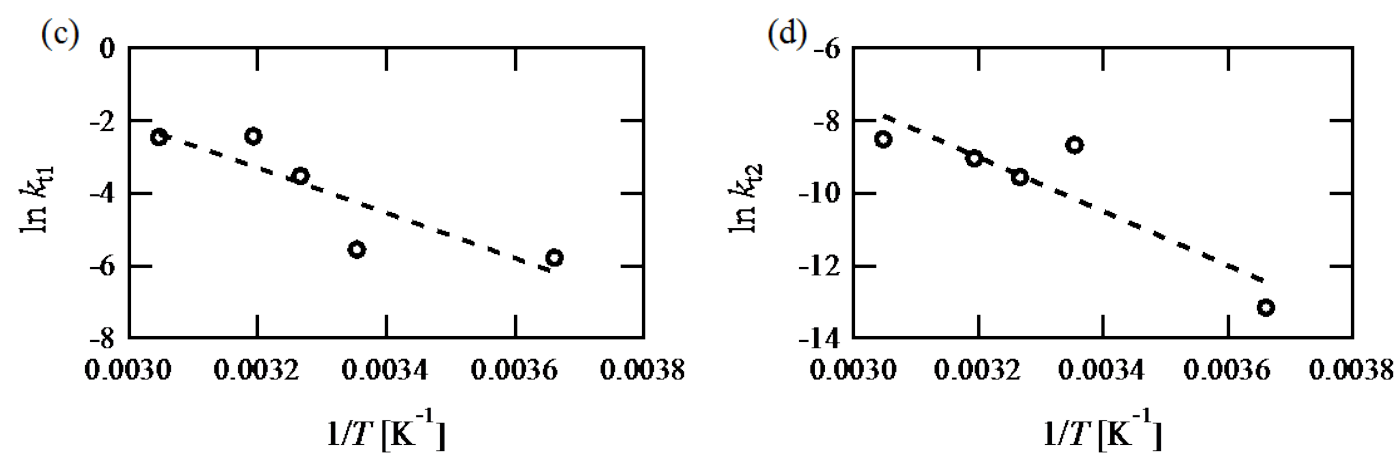

Fig. 4. Arrhenius plots of kinetic parameters: (a) initiation, (b) propagation, (c) termination of a one monomer coordinated Ni complex, and (d) termination of two monomers in a coordinated Ni complex

Table 1 Kinetic constants obtained from Fig. 4.

\begin{tabular}{|c|c|c|c|c|}
\hline & $k_{\mathrm{i} 1}$ & $k_{\mathrm{p}}$ & $k_{\mathrm{t} 1}$ & $k_{\mathrm{t} 2}$ \\
\hline$E$ & $98.0 \mathrm{~kJ} \mathrm{~mol}^{-1}$ & $29.6 \mathrm{~kJ} \mathrm{~mol}^{-1}$ & $51.7 \mathrm{~kJ} \mathrm{~mol}^{-1}$ & $62.1 \mathrm{~kJ} \mathrm{~mol}^{-1}$ \\
\hline \multirow[t]{2}{*}{$k_{0}$} & $1.48 \times 10^{8} \quad \mathrm{~m}^{6}$ & $8.44 \times 10^{3} \quad \mathrm{~m}^{3}$ & $1.59 \times 10^{7} \mathrm{~s}^{-1}$ & $2.90 \times 10^{6} \quad \mathrm{~m}^{3}$ \\
\hline & $\mathrm{mol}^{-2} \mathrm{~s}^{-1}$ & $\mathrm{~mol}^{-1} \mathrm{~s}^{-1}$ & & $\mathrm{~mol}^{-1} \mathrm{~s}^{-1}$ \\
\hline
\end{tabular}

The kinetic model enabled estimation of the concentration profile of active intermediates. Fig. 5 illustrates the estimated concentration of the active intermediate for the experiment at $T=55^{\circ} \mathrm{C}$ (monomer $10 \mathrm{wt} \%$ ), $T=40^{\circ} \mathrm{C}$, (monomer $14 \mathrm{wt} \%$ ), and $T=$ $25^{\circ} \mathrm{C}$, (monomer $10 \mathrm{wt} \%$ ). A higher temperature makes the initiation faster and creates a higher number of active intermediates. The peak was around $10 \mathrm{~s}$ at $T=55^{\circ} \mathrm{C}$ and around $20 \mathrm{~s}$ at $T=40^{\circ} \mathrm{C}$. We tried to utilize the estimation by initiating the reaction at the higher temperature and changing the reaction conditions around the peak of the estimated $\mathrm{P}_{n}{ }^{*}$ concentration. 


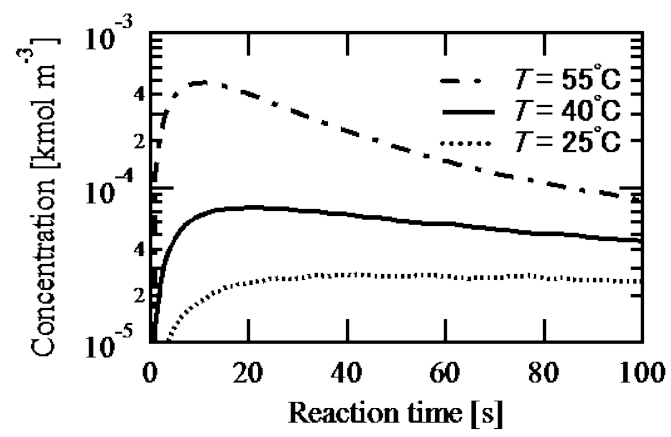

Fig. 5. Concentration profile of $\mathrm{P}_{n}$ * corresponding to (a), (c) and (e) in Fig. 3.

\subsection{Block copolymer synthesis}

To demonstrate the validity and availability of the estimation, we synthesized a block copolymer. After polymerization of monomer A at $40{ }^{\circ} \mathrm{C}$ for $30 \mathrm{~s}$, monomer B was added, and polymerization continued at $25{ }^{\circ} \mathrm{C}$ for $15 \mathrm{~s}$. We intended to make a block of monomer $\mathrm{B}$ by adding an excess amount of monomer $\mathrm{B}$ and by setting the temperature lower after addition so that the deactivation reaction would be suppressed. Fig. 6(a) shows the molecular weight distributions obtained from the designed scheme and control experiment with only the $1^{\text {st }}$ step. The $M_{\mathrm{n}}$ and $M_{\mathrm{w}}$ of the obtained copolymer were $6.6 \times 10^{4}$ and $1.2 \times 10^{5}$, respectively. An apparent shift of the molecular weight from the control was observed, which suggested the sequential growth of the active intermediates generated at the $1^{\text {st }}$ step. Fig. 6(b) indicates the results of GPEC for the obtained polymer in the designed scheme and the homopolymers of monomers A and B. The obtained polymer had three peaks. The small and sharp peak overlapping with monomer A corresponds to the dead polymer generated in the first step. The largest peak around 8 min corresponds to the copolymer, which started polymerization at the first step and continued propagation at the second step. The smallest peak at the position with a slightly longer retention time 
than the homopolymer of monomer B would correspond to the copolymer that began polymerization during the second step. The composition would reflect the monomer concentration at the second step, which consists of a high level of monomer B and a minor level of monomer A that was not consumed in the $1^{\text {st }}$ step. To validate the estimated profile of active intermediates, we conducted the block copolymer synthesis with twice the residence time and half the flow rate. Table 2 compares the conditions and conversion of each monomer species. By increasing the residence time, the conversion of monomer $\mathrm{A}$ naturally increased, but the conversion of monomer B decreased. This tendency can be attributed to the deactivation of the active species during the extended residence time at the $1^{\text {st }}$ step and supports the estimated concentration value of active intermediates, which was decreased in the control scheme.

Based on these pieces of evidence, we can conclude that the estimated profile of active intermediates was valid and we successfully synthesized a block copolymer.
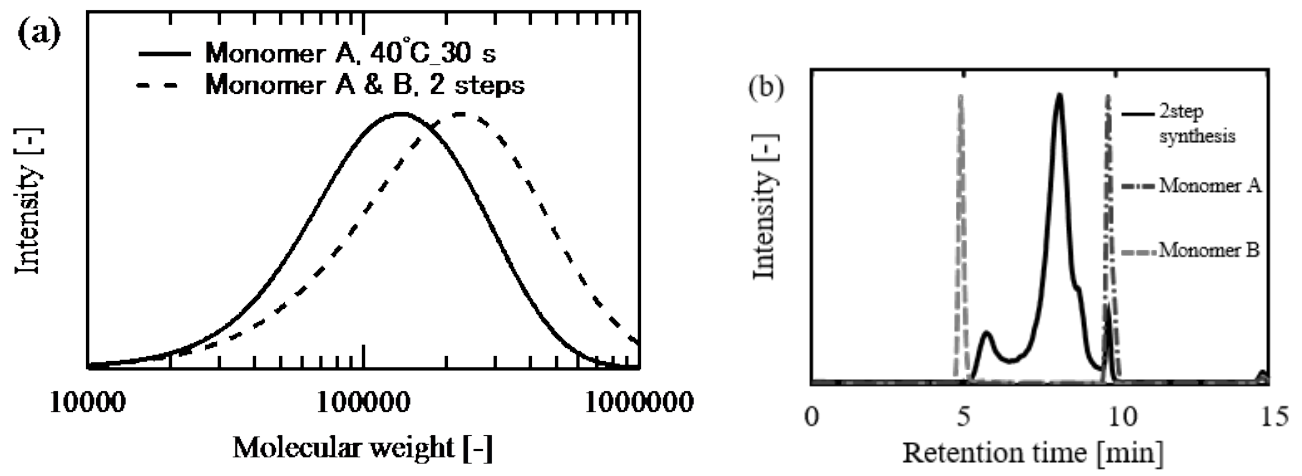

Fig. 6. (a) Molecular weight distribution and (b) GPEC profile of the obtained copolymer

Table 2 Comparison of conversion with different residence times

Residence time $\left(1^{\text {st }}\right.$ Conversion of Conversion of Estimated $\quad \mathrm{P}_{n}{ }^{*}$




\begin{tabular}{llll}
\hline step- $2^{\text {nd }}$ step) [s] & monomer A & monomer B & concentration after \\
& & & the $1^{\text {st }}$ step [M] \\
\hline $30-15 \quad$ (designed & 0.208 & 0.083 & $7.1 \times 10^{-5}$ \\
scheme) & & & \\
60-30 (control & 0.434 & 0.072 & $5.8 \times 10^{-5}$ \\
scheme) & & & \\
\hline
\end{tabular}

\subsection{Homopolymer synthesis with temperature jump}

To synthesize a polymer with a monodispersed molecular weight distribution, it is effective to make the initiation reaction faster than the propagation reaction and to make the termination reaction slower than the other reactions. A higher temperature can boost the initiation reaction, and a lower temperature can efficiently suppress the initiation and termination reactions. We designed the temperature jumping operation for conducting the initiation reaction at the high temperature, $60{ }^{\circ} \mathrm{C}$, and the propagation reaction at the lower temperature, $0{ }^{\circ} \mathrm{C}$. The concentrations of monomer and initiator were fixed at 20 wt $\%$ and $0.033 \mathrm{M}$, respectively. The residence time at $60{ }^{\circ} \mathrm{C}$ was designed based on the kMC simulation. Fig. 7 summarizes the results of the simulation with the kinetic parameters in Table 1 . In the case of the constant temperature operation at $60{ }^{\circ} \mathrm{C}$, the value of $M_{\mathrm{w}} / M_{\mathrm{n}}$ increased almost linearly against the conversion by the simultaneous initiation, propagation and termination reactions. The temperature change had a significant impact on the profile. The $M_{\mathrm{w}} / M_{\mathrm{n}}$ decreased after cooling because the active intermediates generated in the high temperature zone uniformly propagated and terminated. Then, the $M_{\mathrm{w}} / M_{\mathrm{n}}$ increased again with the conversion. This is attributed to the new active 
intermediates generated in the low temperature zone. Rapid cooling after $0.1 \mathrm{~s}$ of reaction at $60{ }^{\circ} \mathrm{C}$ enabled a surprisingly small $M_{\mathrm{w}} / M_{\mathrm{n}}$, around 1.05 , in the minuscule conversion region. The $1.0 \mathrm{~s}$ reaction in the high temperature zone enabled the more stable $M_{\mathrm{w}} / M_{\mathrm{n}}$ curve, although the dead polymer that formed within $1.0 \mathrm{~s}$ increased the $M_{\mathrm{w}} / M_{\mathrm{n}}$. Then, $0.5 \mathrm{~s}$ was determined to be the optimal residence time for the high temperature zone.

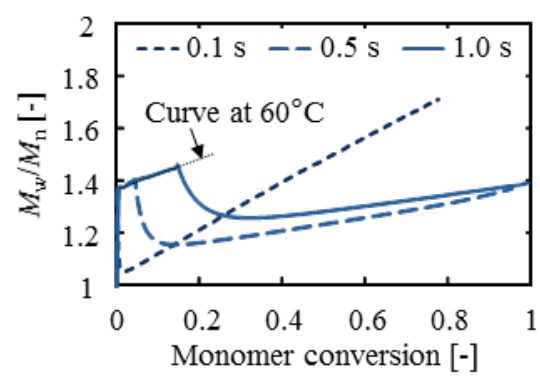

Fig. 7. Simulated $M_{\mathrm{w}} / M_{\mathrm{n}}$ profiles in the case of the temperature jumping operation. The legend shows the residence time in the high temperature zone.

Fig. 8 shows the molecular weight distribution obtained by the designed scheme and constant temperature operation with the same concentration set. The designed scheme successfully resulted in a sharp peak owing to the uniform propagation of active intermediates generated at the high temperature. Table 3 summarizes the experimental and simulation outputs for the designed system and control experiments. The designed scheme showed much higher conversion than the simple summation of $0{ }^{\circ} \mathrm{C}, 30 \mathrm{~s}$ and $60{ }^{\circ} \mathrm{C}, 0.5 \mathrm{~s}$. However, both the conversion and $M_{\mathrm{w}} / M_{\mathrm{n}}$ of the experimental results were worse than those of the simulated values. The most likely reason was the effect of ethyl acetate, which was essential for reducing the molecular weight and preventing clogging, but it was not included in the kinetic model. 


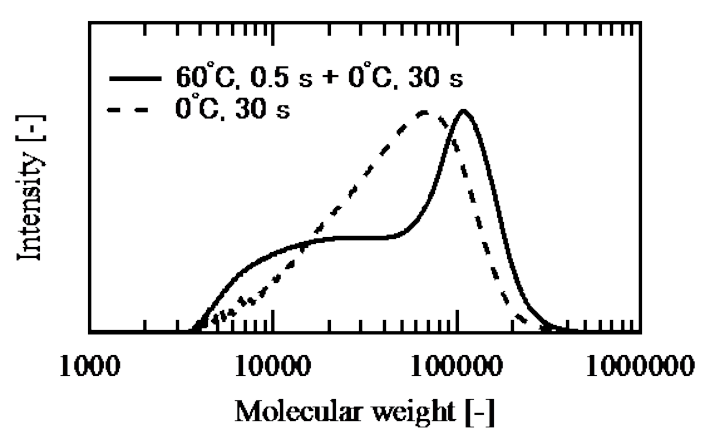

Fig. 8. Molecular weight distributions of the polymers synthesized in the temperature jumping operation from $60{ }^{\circ} \mathrm{C}$ to $0{ }^{\circ} \mathrm{C}$ and the constant temperature operation at $0{ }^{\circ} \mathrm{C}$

Table 3 Output of various schemes: monomer $20 \mathrm{wt} \%$, initiator $0.033 \mathrm{M}$, and $[\mathrm{M}] /[\mathrm{I}]=$ $30 / 1$

\begin{tabular}{lllc}
\hline & conversion [-] & $M_{\mathrm{w}} / M_{\mathrm{n}}$ & $M_{\mathrm{n}}$ \\
\hline $60{ }^{\circ} \mathrm{C}, 0.5 \mathrm{~s}$ & 0.09 & 2.07 & 17909 \\
$0{ }^{\circ} \mathrm{C}, 30 \mathrm{~s}$ & 0.04 & 1.62 & 59792 \\
designed scheme & 0.28 & 1.71 & 72557 \\
designed scheme (simulation) & 0.38 & 1.21 & 65980 \\
\hline
\end{tabular}

\section{Conclusions}

The micro flow reactor was successfully applied to the rate analysis of polymerization by allowing for a short reaction time and rigid temperature control. The validity and utility of the kinetic analysis were demonstrated by synthesizing a block copolymer with a non-living polymerization system. The temperature jumping operation, $0.5 \mathrm{~s}$ initialization at high temperature followed by $30 \mathrm{~s}$ growth at low temperature, was examined based on the estimated kinetic model. Although the experimental results were 
worse than the simulation for the $M_{\mathrm{w}} / M_{\mathrm{n}}$ and conversion, the sharpness values of the molecular weight distribution and productivity were improved from the constant temperature operation. Therefore, a micro flow reactor system supported by reliable kinetic information would be an ideal tool to improve both the productivity and quality of highly functionalized polymers.

\section{Acknowledgments}

We gratefully acknowledge the financial support provided by "the Japan Society for the Promotion of Science” (JSPS), grant numbers 25220913 and 15J00287.

\section{References}

[1] S. Schwolow, A. Neumüller, L. Abahmane, N. Kockmann, T. Röder, Design and application of a millistructured heat exchanger reactor for an energy-efficient process, Chem. Eng. Process. Process Intensif. 108 (2016) 109-116. doi:10.1016/j.cep.2016.07.017.

[2] F. Kaske, S. Dick, S.A. Pajoohi, D.W. Agar, The influence of operating conditions on the mass transfer performance of a micro capillary contactor with liquid-liquid slug flow, Chem. Eng. Process. Process Intensif. 108 (2016) 10-16. doi:10.1016/j.cep.2016.06.010.

[3] R.L. Hartman, J.P. McMullen, K.F. Jensen, Deciding whether to go with the flow: evaluating the merits of flow reactors for synthesis., Angew. Chem. Int. Ed. Engl. 50 (2011) 7502-7519. doi:10.1002/anie.201004637. 
[4] K. Mae, Advanced chemical processing using microspace, Chem. Eng. Sci. 62 (2007) 4842-4851. doi:10.1016/j.ces.2007.01.012.

[5] S. Marre, J. Park, J. Rempel, J. Guan, M.G. Bawendi, K.F. Jensen, Supercritical continuous-microflow synthesis of narrow size distribution quantum dots, Adv. Mater. 20 (2008) 4830-4834. doi:10.1002/adma.200801579.

[6] A. Nagaki, K. Imai, H. Kim, J. Yoshida, Flash synthesis of TAC-101 and its analogues from 1,3,5-tribromobenzene using integrated flow microreactor systems, RSC Adv. 1 (2011) 758-760. doi:10.1039/C1RA00377A.

[7] S. Watanabe, S. Ohsaki, T. Hanafusa, K. Takada, H. Tanaka, K. Mae, et al., Synthesis of zeolitic imidazolate framework-8 particles of controlled sizes, shapes, and gate adsorption characteristics using a central collision-type microreactor, Chem. Eng. J. 313 (2017) 724-733. doi:10.1016/j.cej.2016.12.118.

[8] S. Marre, K.F. Jensen, Synthesis of micro and nanostructures in microfluidic systems, Chem. Soc. Rev. 39 (2010) 1183-1202. doi:10.1039/b821324k.

[9] D.M. Roberge, L. Ducry, N. Bieler, P. Cretton, B. Zimmermann, Microreactor technology: A revolution for the fine chemical and pharmaceutical industries?, Chem. Eng. Technol. 28 (2005) 318-323. doi:10.1002/ceat.200407128.

[10] A. Adamo, R.L. Beingessner, M. Behnam, J. Chen, T.F. Jamison, K.F. Jensen, et al., 
On-demand continuous-flow production of pharmaceuticals in a compact, reconfigurable system, Science (80-. ). 352 (2016) 61-67. doi:10.1126/science.aaf1337.

[11] T. Tsubogo, H. Oyamada, S. Kobayashi, Multistep continuous-flow synthesis of (R)and (S)-rolipram using heterogeneous catalysts, Nature. 520 (2015) 329-332. doi:10.1038/nature14343.

[12] M. Furuta, K. Mukai, D. Cork, K. Mae, Continuous crystallization using a sonicated tubular system for controlling particle size in an API manufacturing process, Chem. Eng. Process. Process Intensif. 102 (2016) 210-218. doi:10.1016/j.cep.2016.02.002.

[13] F. Bally, C. a. Serra, V. Hessel, G. Hadziioannou, Homogeneous polymerization: Benefits brought by microprocess technologies to the synthesis and production of polymers, Macromol. React. Eng. 4 (2010) 543-561. doi:10.1002/mren.201000006.

[14] L.S. Méndez-Portillo, C. Dubois, P. a. Tanguy, Free-radical polymerization of styrene using a split-and-recombination (SAR) and multilamination microreactors, Chem. Eng. J. 256 (2014) 212-221. doi:10.1016/j.cej.2014.05.134.

[15] A. Nagaki, T. Iwasaki, K. Kawamura, D. Yamada, S. Suga, T. Ando, et al., Microflow system controlled carbocationic polymerization of vinyl ethers, Chem. - An Asian J. 3 (2008) 1558-1567. doi:10.1002/asia.200800081.

[16] A. Kumar, J. Hasan, A. Majji, A. Avhale, S. Gopinathan, P. Sharma, et al., Continuous- 
Flow Synthesis of Regioregular Poly(3-Hexylthiophene): Ultrafast Polymerization with High Throughput and Low Polydispersity Index, J. Flow Chem. 4 (2014) 206-210. doi:10.1556/JFC-D-14-00009.

[17] C.G. Dobie, K.V.K. Boodhoo, Surfactant-free emulsion polymerisation of methyl methacrylate and methyl acrylate using intensified processing methods, Chem. Eng. Process. Process Intensif. 49 (2010) 901-911. doi:10.1016/j.cep.2010.08.005.

[18] J. Vandenbergh, T. Tura, E. Baeten, T. Junkers, Polymer end group modifications and polymer conjugations via “click” chemistry employing microreactor technology, J. Polym. Sci. Part A Polym. Chem. 52 (2014) 1263-1274. doi:10.1002/pola.27112.

[19] F. a. Leibfarth, J. a. Johnson, T.F. Jamison, Scalable synthesis of sequence-defined, unimolecular macromolecules by Flow-IEG, Proc. Natl. Acad. Sci. 112 (2015) 1061710622. doi:10.1073/pnas.1508599112.

[20] J. Yoshida, Y. Takahashi, A. Nagaki, Flash chemistry: flow chemistry that cannot be done in batch, Chem. Commun. 49 (2013) 9896-9904. doi:10.1039/C3CC44709J.

[21] S. Asano, T. Maki, K. Mae, Evaluation of mixing profiles for a new micromixer design strategy, AIChE J. 57 (2015) n/a-n/a. doi:10.1002/aic.15082.

[22] B.J. Reizman, K.F. Jensen, Simultaneous solvent screening and reaction optimization in microliter slugs, Chem. Commun. 51 (2015) 2-5. doi:10.1039/C5CC03651H. 
[23] D.A. Barnes, G.M. Benedikt, B.L. Goodall, S.S. Huang, H.A. Kalamarides, S. Lenhard, et al., Addition polymerization of norbornene-type monomers using neutral nickel complexes containing fluorinated aryl ligands, Macromolecules. 36 (2003) 2623-2632. doi:10.1021/ma030001m.

[24] M.M. Mandal, C. Serra, Y. Hoarau, K.D.P. Nigam, Numerical modeling of polystyrene synthesis in coiled flow inverter, Microfluid. Nanofluidics. 10 (2011) 415-423. doi:10.1007/s10404-010-0679-z.

[25] S.K. Kurt, M.G. Gelhausen, N. Kockmann, Axial Dispersion and Heat Transfer in a Milli/Microstructured Coiled Flow Inverter for Narrow Residence Time Distribution at Laminar Flow, Chem. Eng. Technol. 1 (2015) 1122-1130. doi:10.1002/ceat.201400515.

[26] A.B. de Carvalho, P.E. Gloor, A.E. Hamielec, A kinetic mathematical model for heterogeneous Ziegler-Natta copolymerization, Polymer (Guildf). 30 (1989) 280-296. doi:10.1016/0032-3861(89)90118-3.

[27] P.H.M. Van Steenberge, D.R. D’hooge, M.F. Reyniers, G.B. Marin, Improved kinetic Monte Carlo simulation of chemical composition-chain length distributions in polymerization processes, Chem. Eng. Sci. 110 (2014) 185-199. doi:10.1016/j.ces.2014.01.019. 